\title{
Antibiotic Resistance, Phylogenetic Typing and Virulence Genes Profile Analysis of Uropathogenic Escherichia Coli Isolated From Patients in Southern Iraq
}

\section{Mohammed Allami}

Ferdowsi University of Mashhad

\section{Masoumeh Bahreini}

Ferdowsi University of Mashhad

Mohammad Reza Sharifmoghadam ( $\nabla$ sharif@um.ac.ir)

Ferdowsi University of Mashhad https://orcid.org/0000-0002-3638-0653

\section{Research Article}

Keywords: Uropathogenic Escherichia coli. Phylogenetic groups. Antibiotic resistance. Virulence factor genes

Posted Date: April 13th, 2021

DOI: https://doi.org/10.21203/rs.3.rs-401319/v1

License: (c) (i) This work is licensed under a Creative Commons Attribution 4.0 International License. Read Full License

Version of Record: A version of this preprint was published at Journal of Applied Genetics on February 10th, 2022. See the published version at https://doi.org/10.1007/s13353-022-00683-2. 


\section{Abstract}

Of the most common infectious diseases that occur mainly by uropathogenic Escherichia coli (UPEC) is urinary tract infections (UTIs). The purpose of this study was to investigate virulence factors, antibiotic resistance, and phylogenetic groups among UPEC strains isolated from patients with UTI in southern Iraq. A total of 100 UPEC isolates were collected from urine samples of UTI patients from various hospitals in southern Iraq, and confirmed by morphological and biochemical tests. Antimicrobial susceptibility testing on isolates was performed by disk diffusion method. Multiplex PCR technique was used to evaluate the phylogenetic groups and the presence of six virulence factor genes; type 1 fimbria (fimH), A-fimbrial adhesion ( $a f a)$, hemolysin (hly), fimbrial adhesins P (papC), cytotoxic necrosis factor 1 (cnf1), and aerobactin (aer). The majority of isolates belonged to the phylogenetic groups of B2 (55\%) and D (32\%). The most prevalent virulence factors were fimH (96\%), followed by aer (47\%), papC (36\%), cnf1 (17\%), hly (15\%), and afa (8\%). Phenotypic testing showed that the isolates were most resistant to piperacillin, ticarcillin, amoxicillin/clavulanic acid (92\%, 91\%, and $88 \%$, respectively) and most sensitive to amikacin and imipenem, respectively. The maximum antibiotic resistance and virulence factors were observed in the phylogenetic group B2. The results showed that the UPEC isolates had all six virulence factors with high frequency and the highest drug resistance. Besides, the results showed a direct relationship between virulence factors, gene diversity, phylogenetic background, and antimicrobial resistance in the UPEC isolates.

\section{Introduction}

Urinary Tract Infections (UTIs), after respiratory infections, are one of the most common infections among hospitalized patients and referrals to laboratories (Demirci et al., 2019).

Escherichia coli accounts for over $80-90 \%$ of community-acquired UTIs and $30-50 \%$ of hospital-acquired UTIs and is one of the major contributors to hospitalization with severe complications and high healthcare costs. The infection is more prevalent in women, and half of women experience this condition at least once in their lifetime; recurrence of infection is common. There are two pathogenic groups of E.coli, intestinal pathogenic E. coli (InPEC) and extraintestinal pathogenic E. coli (ExPEC) (Kaper et al., 2004; Xia et al., 2015), which include meningitis-associated $E$. coli, sepsis-associated E.coli and uropathogenic E. coli (Ørskov \& Ørskov, 1985). The ExPEC strains, compared with commensal E. coli strains, have bigger genomes and express more virulence factors (Rasko et al., 2008).

Vital virulence factors in the UPEC developing resistance to the host defense system and contributing to adhesion, invasion, and damage to the host cell include adhesins, toxins, siderophores, polysaccharide-based protective coatings, inosines, and serum resistance-related proteins (Johnson et al., 2005). The genes expressing virulence factors are located on bacterial chromosomes, plasmids, and even bacteriophages and can be transferred horizontally or vertically between bacteria (Piatti et al., 2008). The UPEC binds to the epithelial cell lining of the urinary tract with the help of adhesins such as type 1 fimbriae, A-fimbrial ( $a f a)$, fimbrial adhesins P (pap), and S-fimbrial adhesins (sfa) (Dobrindt et al., 2001; Mulvey et al., 1998). Cytotoxic necrosis factor 1 (cnf1) is produced by $40 \%$ of UPECs, which is involved in bacterial spread and survival in urinary tracts. Aerobactin, an iron-chelating agent, confers bacteria the ability of colonizing in iron-deficient environments such as urinary tract (Wiles et al., 2008). The activity of the cytolytic factor of a-hemolysin encoded by hlyA gene contributes to bacterial invasion into the epithelial barrier (Trifillis et al., 1994).

Phylogenetic studies are of particular importance in evaluating the genetic evolution of $E$. coli and can be investigated by polymerase chain reaction (PCR), multi-locus enzyme electrophoresis, or ribotyping. According to phylogenetic studies, there are four major groups A, B1, B2, and D of the E. coli strains (Bonacorsi et al., 2000), which are different in environmental niches, life history characteristics, and tendency to develop disease (Gordon et al., 2008). Most of the 
extraintestinal E. coli strains that producing UTIs belong to the B2 phylogenetic group, and a few falls into group D, with the majority of commensal strains being in group B1 and A. Phylogenetic studies of E.coli using multiplex PCR technique, is based on the presence of two genes, ChuA and YjaA, and anonymous DNA fragment TspE4.C2 (Clermont et al., 2000).

The emergence of antibiotic resistance in pathogenic bacteria is one of the global treatment problems. Currently, reports show that the rate of resistance in UPEC bacteria is increasing. This is especially important in countries with misuse and overuse of antibiotics. Determination of antibiotic resistance patterns in common pathogenic bacteria is important to guide experimental and specific therapies against specific pathogens, including UPEC strains (AlNaqshbandi et al., 2019).

The purpose of this study was to investigate the relationship between virulence factors (involved in adhesion and toxin production) and the antibiotic resistance profile with phylogenetic groups in clinical UPEC strains isolated from outpatient in some hospitals in southern Iraq.

\section{Material And Methods}

\section{Isolation of Escherichia coli strains}

In this study, 385 urine samples were collected from patients with UTI symptoms from May 2017 to January 2018 from Qalat Saleh, Al-Sadr, Al-Zahrawi, and Children Hospital in Maysan Governorate in southern Iraq. In total, 100 clinical isolates (62 females and 38 males) of UPEC were collected. The strains were purified, identified by API 20E Kit (bioMerieux, France), and stored at $-20^{\circ} \mathrm{C}$.

\section{Antibiotic susceptibility}

The antibiogram testing was performed using the Kirby-Bauer disk diffusion method in the Müller-Hinton Agar medium according to the Clinical and Laboratory Standards Institute (CLSI) guidelines (Reller et al., 2009). The commercial antibiotic discs (Bioanalyse, Turkey) used in this study were ticarcillin (75 $\mu \mathrm{g})$, Amoxicillin/clavulanic acid (20/10 $\mu \mathrm{g})$, Piperacillin $(30 \mu \mathrm{g})$, Trimethoprim-Sulfamethoxazole $(1.25 / 23.75 \mu \mathrm{g})$, Doxycycline $(30 \mu \mathrm{g})$, Ceftazidime $(30 \mu \mathrm{g})$, Cefixime $(5 \mu \mathrm{g})$, Ceftriaxone $(10 \mu \mathrm{g})$, Nitrofurantoin $(300 \mu \mathrm{g})$, Aztreonam $(30 \mu \mathrm{g})$, Cefoxitin $(30 \mu \mathrm{g})$, Gentamicin $(10 \mu \mathrm{g})$, Ciprofloxacin $(5 \mu \mathrm{g})$, Norfloxacin $(10 \mu \mathrm{g})$, Amikacin $(30 \mu \mathrm{g})$, and Imipenem $(10 \mu \mathrm{g})$.

\section{Phylotyping and detection of virulence genes}

The DNA was extracted by boiling and stored at $-20^{\circ} \mathrm{C}$ until testing. Two ChuA and YjaA genes and an unidentified DNA fragment TspE4.C2 were used to type isolates based on phylogenetic properties. Also, the prevalence of virolance genes, $f i m \mathrm{H}, a f a, h l y, p a p C, c n f 1$ and aer were analyzed. The phylotype and prevalence of virulence genes were demonstrated using three sets of experiments: group A comprising primers of $f i m \mathrm{H}$, afa, and hly genes; group $\mathrm{B}$ containing primers of papC, cnf1, and aergenes; and group C includes primers of chuA, YjaA, and TspE4.C2 genes. Table 1 shows the sequences of primers used for each gene and the reaction conditions of Multiplex PCR (Bio-Red, Germany) for each gene cluster.

Table 1 Sequences of primers used, the amount of master mix used in each run, and the temperature program of PCR reaction for each primer set (Lee et al., 2016; Sawma-Aouad et al., 2009; Miranda-Estrada et al., 2017). 


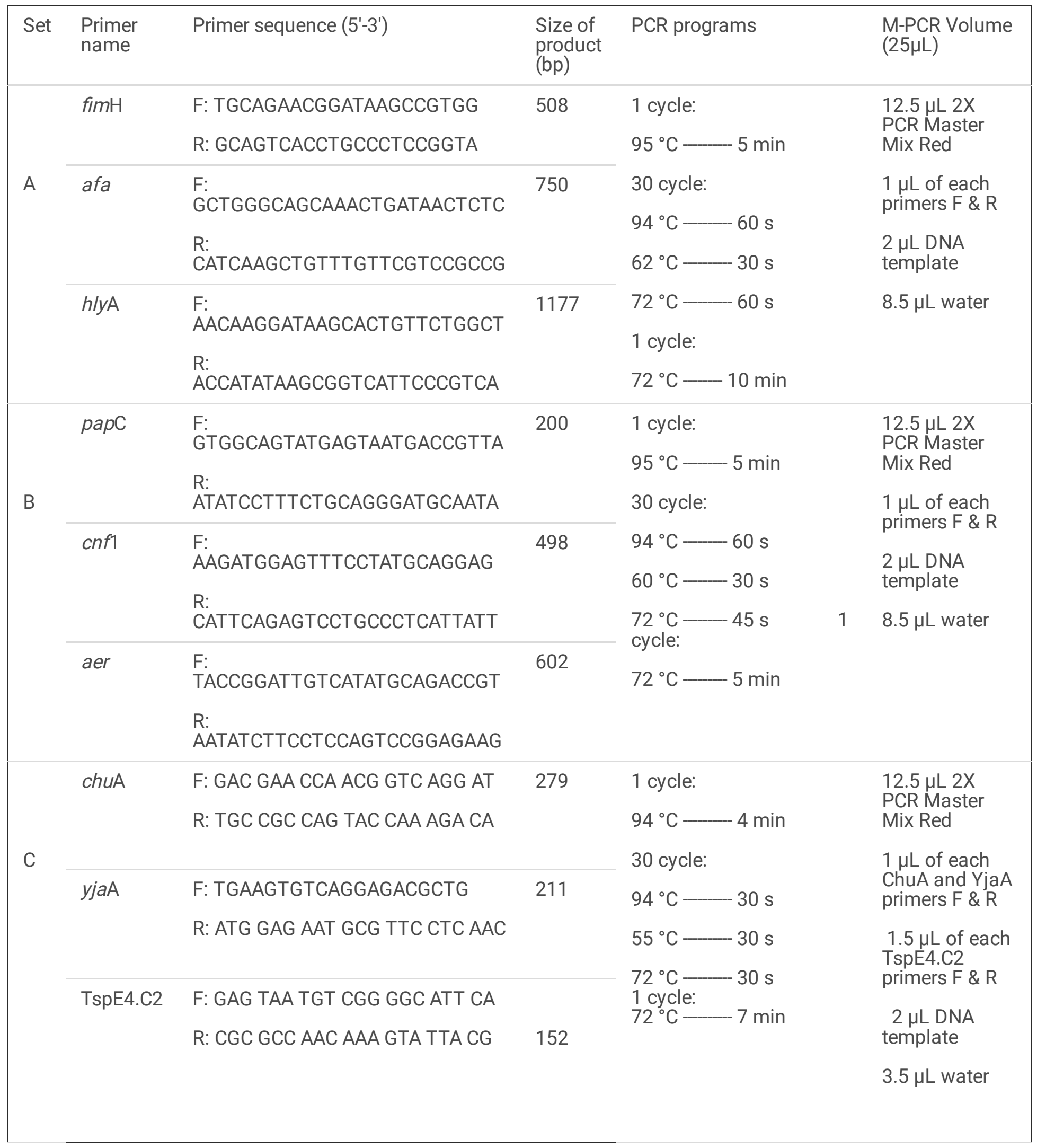

$b p=$ base pairs; $F=$ forward; $R$ = reverse

\section{Statistical analysis}

To compare the occurrence of phenotypic markers in UPEC, Chi-square and two-tailed Fisher's exact tests were used. These tests also were used to describe the association of probable virulence factors with other factors. P $<0.05$ was 
considered statistically significant.

\section{Results}

In total, 100 isolates, of 385 urine specimens from UTI patients, were identified as UPEC and of which, $62 \%$ and $38 \%$ were related to females and males, respectively. The age range of patients in this study was between 4 months and 78 years. The highest prevalence of the disease in all isolates was observed in the age range of 0-5 years (29 samples), followed by 18 patients in the range age of 30-39 years in women and 17 patients in the range age of 20-29 years in men (Fig. 1). There was a statistically significant relationship between the frequency of bacteria and gender $(P=$ 0.006).

\section{Antibiotic resistance profiles}

Among the UPEC isolates tested in this study, resistance rates were as follow: Piperacillin (92\%), Ticarcillin (91\%), Amoxicillin/Clavulanic acid (88\%), Trimethoprim-sulfamethoxazole and Doxycycline (87\%), Cefixime (65\%), Aztreonam (59\%), Ceftriaxone (58\%), Ceftazidime (56\%), Nitrofurantoin (45\%), Cefoxitin (44\%), Norfloxacin and Gentamicin (28\%), Ciprofloxacin (27\%), Amikacin (11\%), and Imipenem (5\%). Also, 94\% of the isolates were resistant to at least three classes of antibiotics (multidrug-resistant, MDR). Statistical results showed that the overall antibiotic resistance rate in male patients was higher than in female patients $(P<0.038)$, and there was a significant relationship between antibiotic resistance and patient age (Fig. 2). The rate of antibiotic resistance has increased in elderly patients ( $P$ $<0.05)$.

\section{Prevalence of virulence genes}

The results showed that $96 \%$ of the isolates had at least one variant of the genes encoding virulence factors (Fig. 3). The highest and lowest prevalence were related to the fim $\mathrm{H}$ gene and the afa gene, respectively. The results also showed a high prevalence of virulence genes among the isolates. The distribution of virulence genes in this study were fimH (96\%), aer (47\%), papC (36\%), cnf1 (16\%), hly (15\%), and afa (8\%) respectively. According to the results, the most frequent gene, fim $\mathrm{H}$, was found in $33 \%$ of isolates; the most two frequent genes, $f i m \mathrm{H}$ and aer, which were identified in $13 \%$ of isolates; the most three frequent genes were $\mathrm{fimH}$, aer, and papC, which were identified in $16 \%$ of the isolates; the most four frequent genes were $f i m \mathrm{H}$, aer, papC, and $c n f 1$, which were identified in $5 \%$ of isolates; and finally, the most five frequent genes were $f i m \mathrm{H}$, aer, $p a p C, c n f 1$, and $h l y$ genes which were identified in $4 \%$ of isolates. A total of six genes together was not detected in any of the isolates.

\section{Prevalence of phylogenetic groups}

The classification of the phylogenetic groups of $E$. coli strains was done by the triplex PCR technique using two genes, ChUA and YjaA, and a DNA fragment of TSPE4.C2 (Fig. 3). The highest prevalence was related to phylogenetic group $\mathrm{B} 2$, and there was no observation of phylogenetic group B1 between the studied isolates. In this study, $55 \%$ of isolates belonged to group $B 2,32 \%$ to group $D$, and $13 \%$ to group $A$.

\section{Relationship between the phylogenetic group and patient profile}

Among phylogenetic groups, group B2 had the highest prevalence in female (59.6\%) and male (50\%) patients. The phylogenetic group D was more prevalent in females (33.8\%) than males (28.9\%). In contrast, group A had the highest prevalence in men $(21 \%)$ than women $(6.4 \%)$. The highest and lowest frequencies of phylogenetic groups were in the range of 0-5 years and 50-78 years, respectively (Fig. 4). No significant difference between the distribution of phylogenetic groups in isolates of male and female patients was shown by statistical analysis. Comparing of the 
prevalence of phylotypes in both sexes showed that phylotype $A$ is more common in isolates of male patients than females $(P=0.047)$.

\section{Virulence gene patterns}

All the studied strains exhibited 17 virulence gene patterns, referred to as Ec. Ec2 was characterized only by the fimH gene's presence and was the most noted pattern found in 33 isolates. Four isolates belonged to the Ec1 pattern that didn't have any virulence genes (Table 2). The B2 group had the highest frequency (15 patterns) among the obtained patterns. Group D and A were present in 9 and 7 patterns, respectively.

Table 2 Virulence gene patterns identified among the studied isolates

\begin{tabular}{|lllllllll|}
\hline pattern & fimH & aer & papC & cnf1 & hlyA & afa & No. of Strains & Phylogenetic groups \\
\hline Ec1 & - & - & - & - & - & - & 4 & \\
\hline Ec2 & + & - & - & - & - & - & 33 & B2, D, A \\
\hline Ec3 & + & + & - & - & - & - & 13 & B2, D, A \\
\hline Ec4 & + & + & + & - & - & - & 16 & B2, D \\
\hline Ec5 & + & + & + & + & - & - & 5 & B2 \\
\hline Ec6 & + & + & + & + & + & - & 4 & B2, D, A \\
\hline Ec7 & + & + & - & - & - & + & 6 & B2, D, A \\
\hline Ec8 & + & - & - & - & + & - & 1 & B2, D \\
\hline Ec9 & + & - & - & + & + & - & 3 & B2, A \\
\hline Ec10 & + & - & + & - & - & - & 3 & B2 \\
\hline Ec11 & + & - & - & - & - & + & 2 & B2, A \\
\hline Ec12 & + & + & + & - & + & - & 2 & D \\
\hline Ec13 & + & + & - & + & + & - & 2 & B2, D \\
\hline Ec14 & + & - & - & + & - & - & 1 & B2 \\
\hline Ec15 & - & + & + & + & - & - & 1 & B2 \\
\hline Ec16 & + & - & + & - & + & - & 3 & \\
\hline Ec17 & + & - & + & + & - & - & 1 & \\
\hline Total & 96 & 47 & 36 & 16 & 15 & 8 & 100 & \\
\hline
\end{tabular}

\section{Distribution of antibiotic resistance among phylogenetic groups}

The highest rates of resistance among phylogenetic groups were group B2 (56.47\%), followed by group A (54.32\%) and group D (42.18\%). Of the 16 antibiotics studied, the most prevalent antibiotic resistance was observed in phylogenetic group B2 with nine antibiotics, including Amoxicillin/Clavulanic acid, Trimethoprim, Sulfamethoxazole, 
Doxycycline, Cefixime, Ceftriaxone, Ceftazidime, Cefoxitin, Norfloxacin, and Gentamicin. Phylogenetic group A showed the highest resistance rate to 5 antibiotics of Aztreonam, Nitrofurantoin, Ciprofloxacin, Amikacin, and Imipenem.

Phylogenetic group D showed the highest resistance rate to 2 antibiotics of Piperacillin and Ticarcillin. The distribution of antibiotic resistance among phylogenetic groups is shown in Table 3. Significant differences were seen between phylogenetic groups and resistance to all anti-infection agents studied, except for Piperacillin, Amikacin, and Ciprofloxacin $(P<0.05)$.

In the present study, the rate of multidrug resistance among the isolates ranged from 3 to 8 classes of antibiotics of which, $94 \%$ of isolates showed MDR resistance to at least three classes of antibiotics. The frequency of samples among the classes of antibiotics showed that most isolates belong to five classes (31.91\%), four classes (25.53\%), and six classes (22.34\%), respectively. The highest prevalence of MDR strains was observed in phylogenetic group B2. The MDR distribution among phylogenetic groups ranks between groups B2 (56.3\%), D (30.8\%), and A (12.7\%), respectively.

Table 3 Distribution of antibiotic resistance among phylogenetic groups

\begin{tabular}{|lllll|}
\hline Drugs & Total Resistance & B2 (55) & D (32) & A (13\%) \\
\hline Piperacillin & $92 \%$ & $50(90.9 \%)$ & $32(100 \%)$ & $10(76.92 \%)$ \\
\hline Ticarcillin & $91 \%$ & $50(90.9 \%)$ & $31(96.87 \%)$ & $10(76.92 \%)$ \\
\hline Amoxicillin clavulanic acid & $88 \%$ & $49(89.09 \%)$ & $28(87.5 \%)$ & $11(84.61 \%)$ \\
\hline Trimethoprim sulfamethoxazole & $87 \%$ & $50(90.9 \%)$ & $27(84.37 \%)$ & $10(76.92 \%)$ \\
\hline Doxycycline & $87 \%$ & $49(89.09 \%)$ & $27(84.37 \%)$ & $11(84.61 \%)$ \\
\hline Cefixime & $65 \%$ & $40(72.72 \%)$ & $18(56.25 \%)$ & $7(53.84 \%)$ \\
\hline Aztreonam & $59 \%$ & $34(61.81 \%)$ & $16(50 \%)$ & $9(69.23 \%)$ \\
\hline Ceftriaxone & $58 \%$ & $34(61.81 \%)$ & $18(56.25 \%)$ & $6(46.15 \%)$ \\
\hline Ceftazidime & $56 \%$ & $31(56.36 \%)$ & $18(56.25 \%)$ & $7(53.84 \%)$ \\
\hline Nitrofurantoin & $45 \%$ & $21(38.18 \%)$ & $15(46.87 \%)$ & $9(69.23 \%)$ \\
\hline Cefoxitin & $44 \%$ & $29(52.72 \%)$ & $10(31.35 \%)$ & $5(38.46 \%)$ \\
\hline Norfloxacin & $28 \%$ & $17(30.90 \%)$ & $7(21.87 \%)$ & $4(30.76 \%)$ \\
\hline Gentamicin & $28 \%$ & $17(30.90 \%)$ & $8(25 \%)$ & $3(23.07 \%)$ \\
\hline Ciprofloxacin & $27 \%$ & $17(30.90 \%)$ & $5(15.62 \%)$ & $5(38.46 \%)$ \\
\hline Amikacin & $11 \%$ & $1(1.81 \%)$ & $1(3.12 \%)$ & $3(23.07 \%)$ \\
\hline Imipenem & $5 \%$ & $261(42.18 \%)$ & $113(54.32 \%)$ \\
\hline Total & & & $0(0 \%)$ & \\
\hline
\end{tabular}

\section{Prevalence of virulence genes between the phylogenetic groups}

Of the 219 virulence genes observed among the strains studied, the highest frequency was seen in phylogenetic group B2 (58.9\%), and the lowest gene prevalence was observed in group D (31.96\%) and group A (9.25\%), respectively. 
Exceptionally, the afa gene had the highest prevalence in groups D and B2, A, respectively. Table 4 shows the prevalence rates of each gene between phylogenetic groups.

Table 4 Prevalence of virulence genes among phylogenetic groups B2, D and A

\begin{tabular}{|llllllll|}
\hline $\begin{array}{l}\text { Phylogenetic } \\
\text { groups }\end{array}$ & fimH (96) & aer(47) & papC (36) & cnf-1 (17) & hlyA (15) & afa (8) & Total (219) \\
\hline B2 (55) & $53(55.2 \%)$ & $29(61.7 \%)$ & $23(63.88 \%)$ & $11(68.75 \%)$ & $10(66.66 \%)$ & $3(37.5 \%)$ & $129(58.9 \%)$ \\
\hline D (32) & $32(33.33 \%)$ & $15(31.91 \%)$ & $10(27.77 \%)$ & $4(25 \%)$ & $5(33.33 \%)$ & $4(50 \%)$ & $70(31.965)$ \\
\hline A (13) & $11(11.45 \%)$ & $3(6.38 \%)$ & $3(8.335)$ & $2(12.5 \%)$ & 0 & $1(12.5 \%)$ & $20(9.25 \%)$ \\
\hline
\end{tabular}

\section{Discussion}

Urinary tract infections, one of the most common human infections, have become a serious risk to public health due to the unexpected increase in antibiotic resistance. The use of molecular phylogenetic classification and the determination of resistance and sensitivity patterns of $E$. coli in patients today can prevent the spread of many resistant infections, and help the economics and health of different communities with appropriate antibiotic treatment (Abd ALameer, 2015).

Our outcomes showed the presence of UTIs in all age groups and an approximately two-fold prevalence in females compared to males (62 females versus 38 males). The anatomical differences in the urinary system between men and women increases the frequency of disease in women; E.coli is part of the normal flora of the gastrointestinal system and urethra is shorter and wider in women increasing the chances of bacterial entry and colonization, resulting in ascending UTI (Dadi et al., 2020). The highest prevalence of the disease was in the age range of 0-5 years, which is not matching with the results of Shah et al. (2019) in Nepal. In a study by Tabasi et al. (2015) in Iran, the most prevalent disease was in the age range of 31-40 years in women and 51-60 years in men, which is consistent with the present results in terms of prevalence of disease in women but not in terms of age. Previous studies have shown that the prevalence of UTI is highly correlated with socioeconomic status, educational level, and sexual activity.

The highest resistance rate among E. coli isolates was related to Piperacillin (92\%) and the lowest resistance rate to Amikacin (11\%) and Imipenem (5\%), which is consistent with the studies performed by others (Ahmed et al., 2019; Salehzadeh and Zamani, 2018). López-Banda et al. (2014) in Mexico showed that resistance to Imipenem (1.9\%) and Amikacin (6.5\%) was lower than other antibiotics. Katongole et al. (2019) in Kampala showed a low rate of resistance to Imipenem (4.5\%). Given these similarities to the lowest antibiotic resistance to Imipenem and Amikacin, it can be suggested that the pattern of antibiotic administration in different parts of the world is the same and that these two drugs may be proposed as the first line of experimental treatment of UTIs.

Physicians usually treat the UTIs empirically, so awareness of epidemiological data in the area is essential to prevent unnecessary use of antibiotics in the treatment of infections and reduce unpleasant outcomes (Flores-Mireles et al., 2015). The outcomes indicated that the majority of isolates were resistant to most antimicrobials tried, and $94 \%$ of the isolates were resistant to more than three classes of antibiotics that were classified in the MDR group (Hadifar et al., 2016). The results showed that the prevalence rate of MDR strains in southern Iraq was higher than in other countries. Compared to others, while North America and Europe have the lowest rates, Asian and African countries appear to experience higher levels of MDR-UPEC, which could be due to inappropriate and overuse of antibiotics in previous years (Ventola, 2015). 
Phylogenetic identification and analysis are a way to study the diversity and characteristics of $E$. coli in order to resolve alternative treatment options and establish control programs (Müştak et al., 2015). The phylogenetic studies revealed that the ExPEC strains are generally positioned in the phylogenetic group B2 and at a lower rate in group D (Ejrnæs, 2011). In the present study, the evaluation of phylogenetic groups for UPEC strains showed that most isolates belonged to phylogenetic group B2 with 55\% prevalence, followed by group D and group A with $32 \%$ and $13 \%$ prevalence, respectively. The results of various studies indicated that the two phylogenetic groups B2 and D, carry more virulence factors. The results and pattern obtained from other studies suggest that most ExPEC strains fall into group B2 and then into group D, which is in agreement with the present study (Lee et al., 2016; Malekzadegan et al., 2018). Unlike some studies, the group B1 was not observed among our isolates, isolates studied in South Korea (Lee et al., 2016). One of the reasons for the differences in the present study results with the above studies can be attributed to differences in the geographical area studied and differences in the number of isolates. Some studies have shown that the highest microbial resistance rates are in phylogenetic group B2 and the lowest resistance rates in phylogenetic group A, which is in line with the present results (Noie Oskouie et al., 2019).

UPEC strains have different types of pathogenic genes that, depending on the presence or absence of some of these factors, lead to the appearance or absence of clinical manifestations. Bacteria can acquire these genes through horizontal transfer and provide flexibility in the size of the bacterial genome (4.5 to $5.5 \mathrm{Mb}$.), so strains with larger genomes will be more pathogenic (Hozzari et al., 2020). Identifying virulence factors, not only indicates the pathogenic process of bacteria, but also plays an important role in the development of vaccines and drugs (Dadi et al., 2020).

The present results also showed that $96 \%$ of the isolates had at least one variant of the genes encoding virulence factors, and the distribution of virulence genes were as follows: fimH (96\%), aer (47\%), papC (36\%), cnf1 (16\%), hly (15\%), and afa (8\%), respectively. fimH, due to its high percentage among UPEC strains and its role in bacterial binding to urinary tract cells and colonization, is considered as a potential candidate to develop vaccine preventing urinary tract infections (Dadi et al., 2020). Bacterial access to iron plays an important role in urinary tract infections (Wiles et al., 2008), and many strains in this study encode the aer gene, which is necessary for iron uptake.

The highest and lowest prevalence of these genes was observed in phylogenetic group B2 and in phylogenetic group A, respectively. The results also exhibited a high prevalence of genes encoding virulence factors among UPEC isolates, which is in agreement with other studies. Lee et al. (2016) and Tarchouna et al. (2013) reported the highest and lowest prevalence of fimH and afa genes, respectively, among UPEC isolates, which is consistent with the present study. Also, our results were consistent with the results of Yilmaz and Aslantas (2020) that showed the genes, fim $\mathrm{H}, \mathrm{papC}, \mathrm{afa}, \mathrm{aer}$, $h l y$, and cnf1 highly distributed among all isolates.

In this study, the isolates were divided into 17 patterns (Ec1-Ec17) based on the distribution of virulence genes; the pattern Ec2 containing only the fimH gene was the most prevalent pattern with 33 samples. The lowest prevalence of virulence genes was observed in Ec14, Ec17, Ec8, and Ec15 patterns with only one isolate. Also, none of the six genes were detected in the four isolates belonging to the Ec1 pattern. Out of 17 different patterns, the phylogenetic group B2 was present in 15 patterns, phylogenetic group D in 9 patterns, and phylogenetic group $A$ in 7 patterns. These results are consistent with the findings by Jalali et al. (2015) in Iran. Ali Abdi et al. (2015) detected 31 different patterns and reported that phylogenetic group B2 was present in most patterns (15 patterns). However, phylogenetic groups D and A each were present in 9 patterns, roughly in agreement with the results of the present study in terms of the prevalence of virulence genes in phylogenetic groups. Tarchouna et al. (2013) in Tunisia positioned the UPEC isolates in 23 patterns that were slightly different from the present study in the distribution of virulence genes, and reported the highest prevalence belonged to fim $\mathrm{H}$ gene. 


\section{Conclusion}

In this study, the polymerase chain reaction technique was used to classify the uropathogenic Escherichia coli isolates into phylogenetic groups. The results showed that the highest prevalence rates in the studied isolates were related to phylogenetic groups B2 and D. Therefore, it can be stated that the isolates have high pathogenicity having virulence genes highly, as the results of different studies indicate that the two phylogenetic groups, B2 and D, carry more virulence factors than the phylogenetic groups B1 and A. The high resistance of the isolates to antibiotics indicates that it is necessary to detect resistant strains rapidly and timely in order to select appropriate treatment options and to prevent the spread of resistance. Also, it is recommended that urinary tract infections should be treated according to the regional pattern of sensitivity and resistance in order to prevent the spread of drug-resistant strains. The results of the present study showed that the urine of patients with urinary tract infection could be a potential source for the spread of $E$. coli strains with different virulence and resistance factors. Therefore, according to the high prevalence of urinary tract infection, the distribution of resistance and virulence factors, and the therapeutic failure, consequently, pyelonephritis, cystitis, and prostatitis, it is necessary to detect these strains promptly and accurately.

\section{Declarations}

\section{Acknowledgements}

The authors thank the laboratory staff of Qalat Saleh Hospital, especially bacteriologist Faten Al-Azzawi, for their cooperation in conducting this research.

\section{Funding}

This work was supported by the Ferdowsi University of Mashhad [grant numbers 3/46008].

\section{Competing interests}

The authors declare that they have no competing interests.

\section{Ethics approval}

This study was granted approval by the Ferdowsi University of Mashhad [IR.UM.REC.1399.046] for studies on participants giving informed consent.

Consent to participate: Not applicable

Consent for publication: Not applicable

Availability of data and material: Not applicable

Code availability: Not applicable

\section{Authors' contributions}

MRS and MB participated in the study design and experiments. MA conducted experiments. MRS, MB and MA contributed to the data analysis and wrote the primary draft of the manuscript, reviewed and revised the paper. All authors have read and approved the final manuscript. 
1. Abd ALameer, R (2015) Genotyping of Escherichia coli Isolated From Clinical and Hospitals Environment. Univ ThiQar J Sci 5:3-13.

2. Ahmed N, Zeshan B, Naveed M, Afzal M, Mohamed M (2019) Antibiotic resistance profile in relation to virulence genes fimH, hlyA and usp of uropathogenic E. coli isolates in Lahore, Pakistan. Trop Biomed 36:559-68.

3. Ali Abdi H, Rashki Ghalehnoo M (2015) Virulence genes, genetic diversity, antimicrobial susceptibility and phylogenetic background of Escherichia coli isolates. Int J Enteric Pathog 3(3):1-7. doi: 10.17795/ijep25692.

4. Al-Naqshbandi AA, Chawsheen MA, Abdulqader HH (2019) Prevalence and antimicrobial susceptibility of bacterial pathogens isolated from urine specimens received in rizgary hospital-Erbil. J Infect Public Health 12:330-6. doi: 10.1016/j.jiph.2018.11.005.

5. Bonacorsi SPP, Clermont O, Tinsley C, Le Gall I, Beaudoin J-C, Elion J, Nassif X, Bingen E (2000) Identification of Regions of the Escherichia coli Chromosome Specific for Neonatal Meningitis-Associated Strains. Infect Immun 68:2096-101. doi: 10.1128/iai.68.4.2096-2101.2000.

6. Clermont O, Bonacorsi S, Bingen E (2000) Rapid and simple determination of the Escherichia coli phylogenetic group. Appl Environ Microbiol 66(10):4555-4558. doi: 10.1128/aem.66.10.4555-4558.2000

7. Dadi BR, Abebe T, Zhang L, Mihret A, Abebe W, Amogne W (2020) Distribution of virulence genes and phylogenetics of uropathogenic Escherichia coli among urinary tract infection patients in Addis Ababa, Ethiopia. BMC Infect Dis 20(1): 108

8. Demirci M, Ünlü Ö, Tosun Ai (2019) Detection of O25b-ST131 clone, CTX-M-1 and CTX-M-15 genes via real-time PCR in Escherichia coli strains in patients with UTIs obtained from a university hospital in Istanbul. J Infect Public Health 12(5):640-644. doi: 10.1016/j.jiph.2019.02.017

9. Dobrindt U, Blum-Oehler G, Hartsch T, Gottschalk G, Ron EZ, Fünfstück R, Hacker J (2001) S-Fimbria-Encoding Determinant sfa I Is Located on Pathogenicity Island III536 of Uropathogenic Escherichia coli Strain 536. Infect Immun 69:4248-56. doi: 10.1128/IAI.69.7.4248-4256.2001

10. Ejrnæs K (2011) Bacterial characteristics of importance for recurrent urinary tract infections caused by Escherichia coli. Dan Med Bull, 58 (2011) B4187.

11. Flores-Mireles AL, Walker JN, Caparon M, Hultgren SJ (2015) Urinary tract infections: Epidemiology, mechanisms of infection and treatment options. Nat Rev Microbiol 13: 269-84. doi.org/10.1038/nrmicro3432.

12. Gordon DM, Clermont O, Tolley H, Denamur E (2008) Assigning Escherichia coli strains to phylogenetic groups: multi-locus sequence typing versus the PCR triplex method. Environ Microbiol 10:2484-96. doi: 10.1111/j.14622920.2008. 01669.x

13. Hadifar S, Moghoofei M, Nematollahi S, Ramazanzadeh R, Sedighi M, Salehi-Abargouei A, Miri A (2016) Epidemiology of multi drug resistant uropathogenic Escherichia coli in Iran: a systematic review and metaanalysis. Jpn J Infect Dis 70(2016):19-25. doi: 10.7883/yoken.JJID.2015.652.

14. Hozzari, A., Behzadi, P., Khiabani, P. K., Sholeh, M., \& Sabokroo, N. (2020). Clinical cases, drug resistance, and virulence genes profiling in Uropathogenic Escherichia coli. J Appl Genet 1-9

15. Jalali HR, Pourbakhsh A, Fallah F, Eslami G (2015) Genotyping of virulence factors of Uropathogenic Escherichia coli by PCR. Nov Biomed 3:177-81.

16. Johnson JR, Kuskowski MA, O'bryan TT, Colodner R, Raz R (2005) Virulence genotype and phylogenetic origin in relation to antibiotic resistance profile among Escherichia coli urine sample isolates from Israeli women with acute uncomplicated cystitis. Antimicrob Agents Chemother 49:26-31. doi: 10.1128/AAC.49.1.26-31.2005.

17. Kaper JB, Nataro JP, Mobley HLT (2004) Pathogenic Escherichia coli. Nat Rev Microbiol 4:123-40. doi: 10.1038/nrmicro818.

Page $11 / 16$ 
18. Katongole P, Kisawuzi DB, Bbosa HK, Kateete DP, Najjuka CF (2019) Phylogenetic groups and antimicrobial susceptibility patterns of uropathogenic Escherichia coli clinical isolates from patients at Mulago National Referral Hospital, Kampala, Uganda. F1000Research, 8(1828), 1828.

19. Lee JH, Subhadra B, Son YJ, Kim DH, Park HS, Kim JM, Koo SH, Oh MH, Kim HJ, Choi CH (2016) Phylogenetic group distributions, virulence factors and antimicrobial resistance properties of uropathogenic Escherichia coli strains isolated from patients with urinary tract infections in South Korea. Lett Appl Microbiol 62:84-90. https://doi.org/10.1111/lam.12517.

20. López-Banda DA, Carrillo-Casas EM, Leyva-Leyva M, Orozco-Hoyuela G, Manjarrez-Hernández ÁH, ArroyoEscalante S, Moncada-Barrón D, Villanueva-Recillas S, Xicohtencatl-Cortes J, Hernández-Castro R (2014) Identification of virulence factors genes in Escherichia coli isolates from women with urinary tract infection in Mexico. Biomed Res Int 2014:959206. doi: 10.1155/2014/959206.

21. Malekzadegan Y, Khashei R, Ebrahim-Saraie HS, Jahanabadi Z (2018) Distribution of virulence genes and their association with antimicrobial resistance among uropathogenic Escherichia coli isolates from Iranian patients. BMC Infect Dis, 18(1):572. doi: 10.1186/s12879-018-3467-0.

22. Miranda-Estrada LI, Ruíz-Rosas M, Molina-López J, Parra-Rojas I, González-Villalobos E, Castro-Alarcón N (2017) Relationship between virulence factors, resistance to antibiotics and phylogenetic groups of uropathogenic Escherichia coli in two locations in Mexico. Enferm Infecc Microbiol Clin 35:426-33. doi: 10.1016/j.eimc.2016.02.021.

23. Mulvey MA, Lopez-Boado YS, Wilson CL, Roth R, Parks WC, Heuser J, Hultgren SJ (1998) Induction and evasion of host defenses by type 1-piliated uropathogenic Escherichia coli. Science 282(5393):1494-1497. doi:

10.1126/science.282.5393.1494.

24. Müştak, H. K., Günaydin, E., Kaya, İ. B., Salar, M. Ö., Babacan, O., Önat, K., ... \& Diker, K. S. (2015). Phylo-typing of clinical Escherichia coli isolates originating from bovine mastitis and canine pyometra and urinary tract infection by means of quadruplex PCR. Vet Q 35(4): 194-199

25. Noie Oskouie A, Hasani A, Ahangarzadeh Rezaee M, Soroush Bar Haghi MH, Hasani A, Soltani E (2019) A Relationship Between O-Serotype, Antibiotic Susceptibility and Biofilm Formation in Uropathogenic Escherichia coli. Microb Drug Resist 25:951-8. doi: 10.1089/mdr.2018.0330.

26. Piatti G, Mannini A, Balistreri M, Schito AM (2008) Virulence factors in urinary Escherichia coli strains: phylogenetic background and quinolone and fluoroquinolone resistance. J Clin Microbiol 46:480-7. doi: 10.1128/JCM.01488-07.

27. Ørskov I, Ørskov F (1985) Escherichia coli in extra-intestinal infections. Epidemiol Infect 95:551-75.

28. Rasko DA, Rosovitz MJ, Myers GSA, Mongodin EF, Fricke WF, Gajer P, Crabtree J, Sebaihia M, Thomson NR, Chaudhuri R (2008) The pangenome structure of Escherichia coli: comparative genomic analysis of E. coli commensal and pathogenic isolates. J Bacteriol 190:6881-93. doi: 10.1128/JB.00619-08

29. Reller LB, Weinstein M, Jorgensen JH, Ferraro MJ (2009) Antimicrobial susceptibility testing: a review of general principles and contemporary practices. Clin Infect Dis 49:1749-55. doi:org/10.1086/647952

30. Salehzadeh A, Zamani H (2018) Characterization of (Uropathogenic) E. coli isolated from urinary tract infections: phylogenetic typing and distribution of virulence-associated traits. Br J Biomed Sci 75:40-42. doi.org/10.1080/09674845.2017.1336834.

31. Sawma-Aouad G, Hashwa F, Tokajian S (2009) Antimicrobial resistance in relation to virulence determinants and phylogenetic background among uropathogenic Escherichia coli in lebanon. J Chemother 21:153-8. https://doi.org/10.1179/joc.2009.21.2.153. 
32. Shah C, Baral R, Bartaula B, Shrestha LB (2019) Virulence factors of uropathogenic Escherichia coli (UPEC) and correlation with antimicrobial resistance. BMC Microbiol 19:204. doi.org/10.1186/s12866-019-1587-3.

33. Tabasi M, Asadi Karam M R, Habibi M, Yekaninejad MS, Bouzari S (2015) Phenotypic Assays to Determine Virulence Factors of Uropathogenic Escherichia coli (UPEC) Isolates and their Correlation with Antibiotic Resistance Pattern. Osong Public Heal Res Perspect, 6 (2015):261-8. doi.org/10.1016/j.phrp.2015.08.002.

34. Tarchouna M, Ferjani A, Ben-Selma W, Boukadida J (2013) Distribution of uropathogenic virulence genes in Escherichia coli isolated from patients with urinary tract infection. Int J Infec Dis 17(6):e450-e453. doi: 10.1016/j.ijid.2013.01.025.

35. Trifillis AL, Donnenberg MS, Cui X, Russell RG, Utsalo SJ, Mobley HLT, Warren JW (1994) Binding to and killing of human renal epithelial cells by hemolytic P-fimbriated E. coli. Kidney Int 46:1083-91. doi: 10.1038/ki.1994.370.

36. Ventola CL (2015) The antibiotic resistance crisis: part 1: causes and threats. Pharm Ther 40:277-83. doi: 10.7883/yoken.JJID.2015.652.

37. Wiles TJ, Kulesus RR, Mulvey MA (2008) Origins and virulence mechanisms of uropathogenic Escherichia coli. Exp Mol Pathol 85:11-9. doi: 10.1016/j.yexmp.2008.03.007

38. Xia P, Zou Y, Wang Y, Song Y, Liu W, Francis DH, Zhu G (2015) Receptor for the F4 fimbriae of enterotoxigenic Escherichia coli (ETEC). Appl Microbiol Biotechnol 99:4953-9. doi: 10.1007/s00253-015-6643-9.

39. Yılmaz EŞ, Aslantaş Ö (2020) Phylogenetic Group/Subgroups Distributions, Virulence Factors, and Antimicrobial Susceptibility of Escherichia coli Strains from Urinary Tract Infections in Hatay. Revista Da Sociedade Brasileira de Medicina Tropical 53. doi.org/10.1590/0037-8682-0429-2019

\section{Figures}

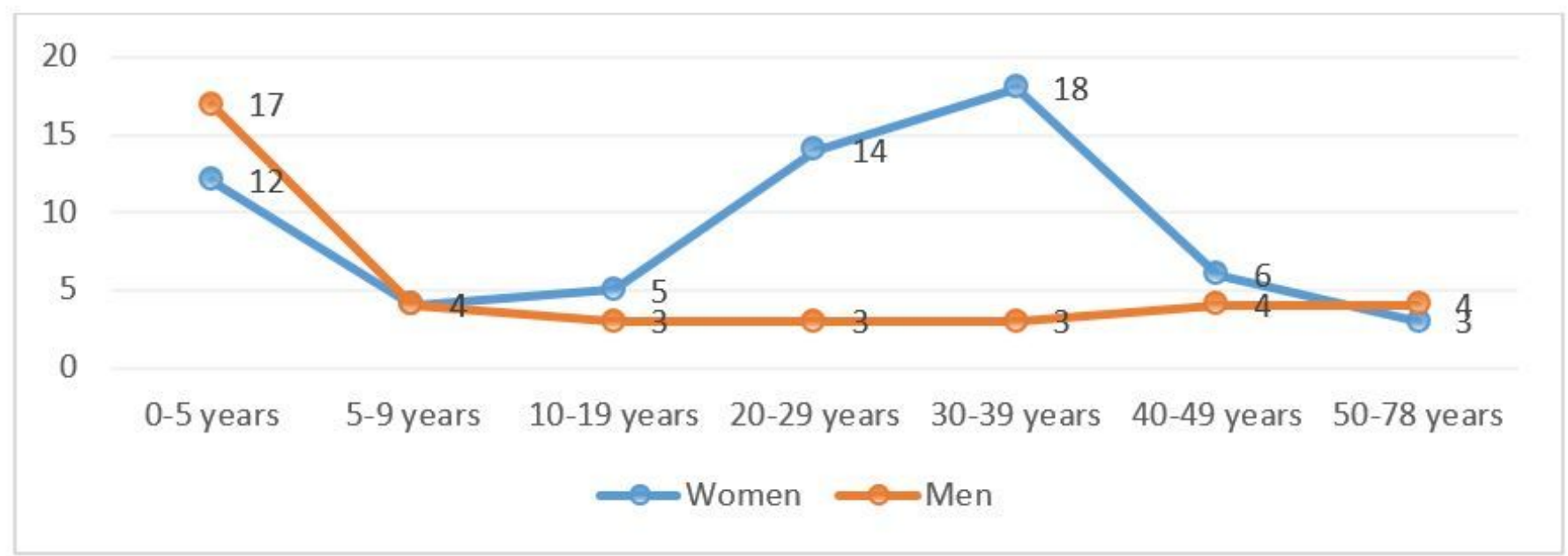

\section{Figure 1}

Disease distribution among different age groups 


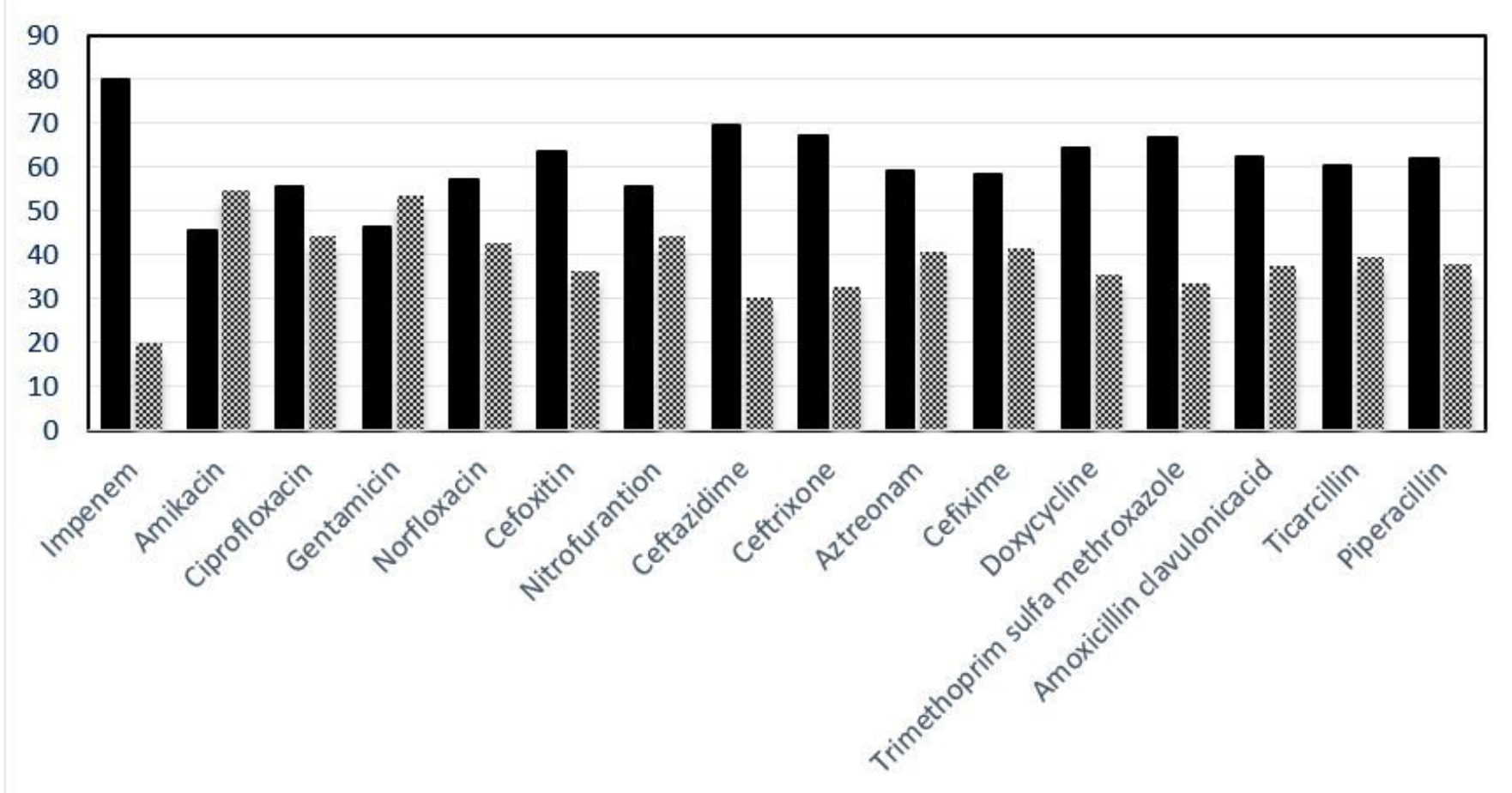

-Women Men

Figure 2

Antibiotic resistance profile 


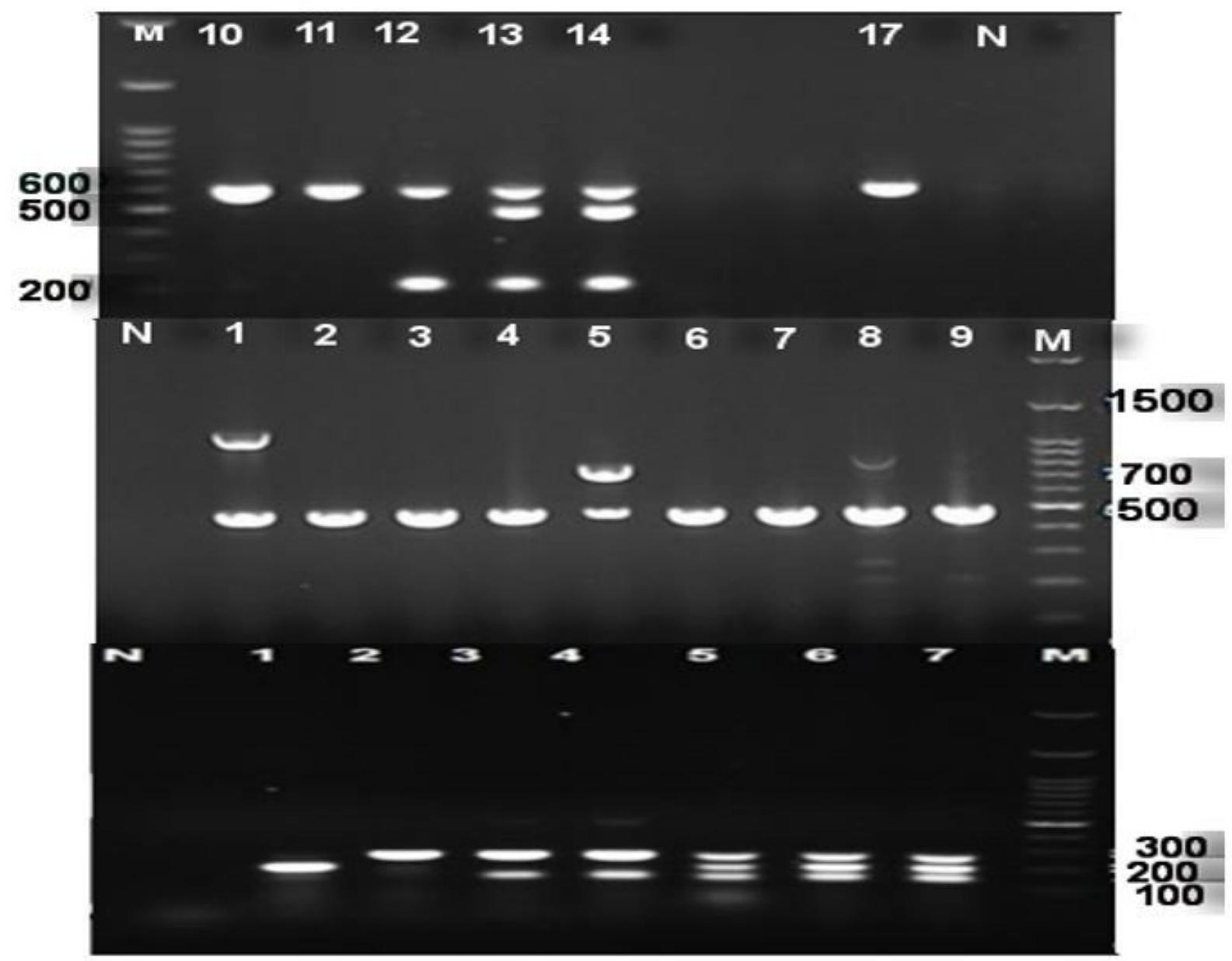

\section{Figure 3}

Results of multiplex PCR specific for virulence factors. M (DNA ladder 100 bp, Fermentase co.), 1 to 9 positive for fimH(508 bp), 5 and 8 positive for afa (750 bp), 1 positive for hly (1177 bp), 10-14 and 17 positives for aer (602 bp), 13 and 14 positive for cnf1 (498 bp), 12,13 and 14 positive for papC (200 bp), N (Negative control). Triplex PCR profiles specific for $E$. coli phylogenetic groups. $M$, marker; $N$, negative control; 1 , group $A ; 2,3$ and 4, group $D ;$ well 5,6 and 7 group B2. 


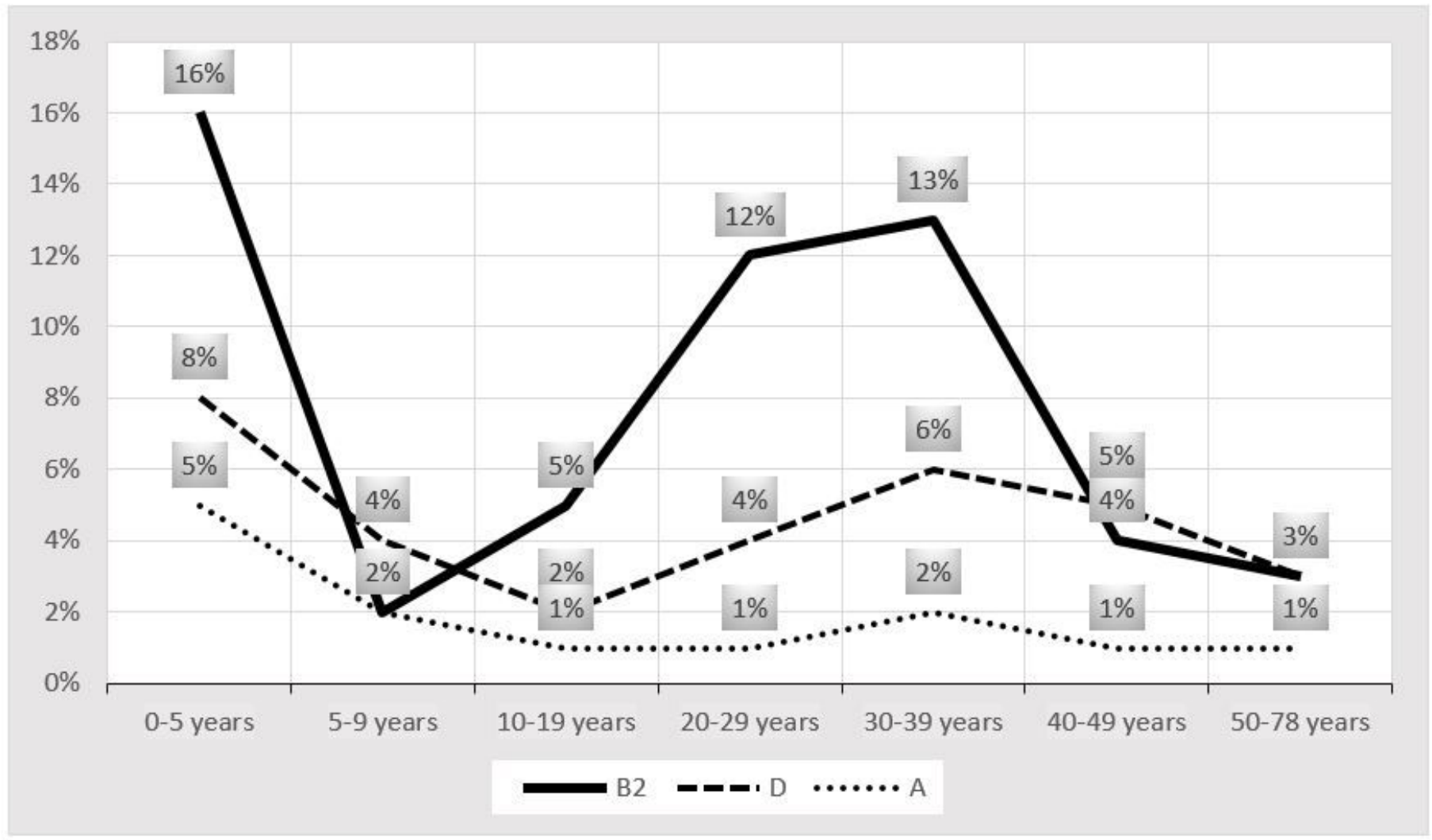

Figure 4

Relationship between phylogenetic groups and patient age 